\title{
Manganese-Enhanced Magnetic Resonance Imaging (MEMRI)
}

\author{
Cynthia A. Massaad and Robia G. Pautler
}

\begin{abstract}
The use of manganese ions $\left(\mathrm{Mn}^{2+}\right)$ as an MRI contrast agent was introduced over 20 years ago in studies of $\mathrm{Mn}^{2+}$ toxicity in anesthetized rats (1). Manganese-enhanced MRI (MEMRI) evolved in the late nineties when Koretsky and associates pioneered the use of MEMRI for brain activity measurements (2) as well as neuronal tract tracing (3). Currently, MEMRI has three primary applications in biological systems: (1) contrast enhancement for anatomical detail, (2) activitydependent assessment and (3) tracing of neuronal connections or tract tracing. MEMRI relies upon the following three main properties of $\mathrm{Mn}^{2+}:(1)$ it is a paramagnetic ion that shortens the spin lattice relaxation time constant $\left(T_{1}\right)$ of tissues, where it accumulates and hence functions as an excellent $T_{1}$ contrast agent; (2) it is a calcium $\left(\mathrm{Ca}^{2+}\right)$ analog that can enter excitable cells, such as neurons and cardiac cells via voltage-gated $\mathrm{Ca}^{2+}$ channels; and (3) once in the cells $\mathrm{Mn}^{2+}$ can be transported along axons by microtubule-dependent axonal transport and can also cross synapses trans-synaptically to neighboring neurons. This chapter will emphasize the methodological approaches towards the use of MEMRI in biological systems.
\end{abstract}

\section{Keywords}

MEMRI; rodents; manganese; central nervous system; contrast agent; MRI

\section{Introduction}

$\mathrm{Mn}^{2+}$ is a trace element essential for normal body function and development throughout the lifespan of mammals (4). Most notably $\mathrm{Mn}^{2+}$ is an essential cofactor for several enzymes responsible for a wide variety of physiological body functions (4). Such enzymes include manganese superoxide dismutase (5) which is essential for oxidative stress prevention, pyruvate carboxylase (6) which plays a critical role in gluconeogenesis, arginase (7) which is involved in urea production by the liver, and glutamine synthetase (8), an astrocytespecific enzyme regulated by about $80 \%$ of brain $\mathrm{Mn}^{2+}$. The importance of $\mathrm{Mn}^{2+}$ is illustrated by studies linking disruption of $\mathrm{Mn}^{2+}$ homeostasis to disease occurrence $(5,9)$. $\mathrm{Mn}^{2+}$ deficiency has been linked to deficient bone metabolism in rats (10), as well as skin lesions, bone malformation, epileptic seizures, and increased $\mathrm{Ca}^{2+}$ and phosphorous levels in humans (11). Although $\mathrm{Mn}^{2+}$ deficiency is clearly associated with adverse effects, the aforementioned studies were achieved with an artificially induced $\mathrm{Mn}^{2+}$-deficient diet (11). No naturally occurring $\mathrm{Mn}^{2+}$-deficiency related diseases have been observed. However, $\mathrm{Mn}^{2+}$ is more frequently of toxicological concern. Although it is considered the least toxic of all essential elements (12), excessive exposure to the metal leads to central nervous system toxicity (4). It has been shown that $\mathrm{Mn}^{2+}$ can enter the central nervous system either directly via the olfactory receptor neurons or through the blood brain barrier by diffusion or active transport $(13,14)$. Once in the nervous system, $\mathrm{Mn}^{2+}$ is transported along neurons by microtubule-dependent axonal transport $(15,16)$ and can traverse synapses to accumulate in neighboring neurons $(17,18)$. The resulting neurotoxicity preferentially targets the striatum 
leading to Parkinson's disease-like symptoms, including generalized bradykinesia, widespread rigidity, tremors, hallucinations, and memory loss $(4,19,20)$.

In addition to multiple roles in normal physiology, $\mathrm{Mn}^{2+}$ is also a $\mathrm{Ca}^{2+}$ analog and can enter excitable cells via several types of $\mathrm{Ca}^{2+}$ channels such as voltage-gated $\mathrm{Ca}^{2+}$ channels and the $\mathrm{Na}^{+} / \mathrm{Ca}^{2+}$ exchanger (21-24). $\mathrm{Mn}^{2+}$ also accumulates in mitochondria via the mitochondrial $\mathrm{Ca}^{2+}$ uniporter $(25,26)$. The analogy of $\mathrm{Mn}^{2+}$ with $\mathrm{Ca}^{2+}$ resulted in the use of $\mathrm{Mn}^{2+}$ as a fura-2 quencher and hence $\mathrm{Ca}^{2+}$ indicator in biological systems by fluorescence microscopy (27-31).

Another very important feature of $\mathrm{Mn}^{2+}$ is that it is paramagnetic and produces MR contrast by causing a strong reduction in the $T_{1}$ relaxation times of water (32-35). Positive contrast is detected in $T_{1}$-weighted images of tissues where $\mathrm{Mn}^{2+}$ accumulates (32-35).

The combined physical and biological properties of $\mathrm{Mn}^{2+}$ make it a useful contrast agent for anatomical and functional imaging in multiple systems. Indeed, manganese-enhanced MRI (MEMRI) has been gaining growing interest in the past few years $(2,3,36,37)$ and currently has three main applications for biological systems. First, owing to its contrastenhancing properties, systemic $\mathrm{Mn}^{2+}$ injections are used for enhancement of the brain cytoarchitecture for anatomical studies (38-44). This technique has been used in adult, as well as in young developing organisms. Its use has further been extended to studying the development of embryos in utero (45). Second, given that $\mathrm{Mn}^{2+}$ can enter cells via voltagegated $\mathrm{Ca}^{2+}$ channels, it is used as a marker of activity in specific protocols that promote its accumulation in active brain areas (2, 46-52). This use of MEMRI is termed activationinduced MEMRI or AIM-MRI. AIM-MRI also has applications in the heart because of the high concentration of $\mathrm{Ca}^{2+}$ channels (53). This protocol, however, will emphasize MEMRI applications in the nervous system. The third and last application of MEMRI is tract tracing; given that $\mathrm{Mn}^{2+}$ is transported by microtubule-dependent axonal transport and can cross synapses to reach post-synaptic neurons, MEMRI has been used as a neuronal tract tracer for several neuronal pathways including the visual, olfactory, and somatosensory pathways, in a variety of animal models, such as mice, rats, monkeys, and birds $(3,54-63)$. This review will focus on MEMRI applications in rodents. The versatility of MEMRI is also demonstrated by the development of methods for dynamic $\mathrm{Mn}^{2+}$ transport imaging, which are proving as useful markers of disease and related therapy $(64,65)$. The following chapter will expand upon each of the three applications of MEMRI with special emphasis on techniques related to each application.

\section{Materials}

\subsection{Anatomical Contrast Enhancement}

\subsubsection{Intravenous $\mathrm{MnCl}_{2}$}

1. $\mathrm{MnCl}_{2}$ as a source of $\mathrm{Mn}^{2+}$

2. Sterile water

3. Sterile saline

4. Beaker of warm water for tail warming and dilation of the tail vein

5. 27- or 30-gauge needle

6. Forceps

7. 1-ml syringes

8. Tubing suitable to attach to a 27 -gauge needle 
9. Pre-anesthetic (e.g., glycopyrrolate)

10. Anesthetic (e.g., isoflurane)

11. Analgesic (e.g., bupivicaine)

12. Sterile saline

13. Tape

14. 4-gauge nylon suture

15. Syringe pump

16. Warming blanket

17. Small animal-monitoring system complete with rectal temperature probe and respiration sensor

18. Neuromuscular blocking agent (pancuronium bromide or gallamine triethiodide)

19. Ventilator

\subsection{Activation-Induced MRI}

\subsubsection{Intravenous $\mathrm{MnCl}_{2}$ - see Section 2.1.1.}

\subsubsection{Blood Brain Barrier (BBB) Disruption}

\subsubsection{Hyperosmolar Mannitol Infusion}

- This requires the infusion of mannitol through the tail vein (or femoral vein). Materials will be identical to Section 2.1 with the exception of using a 5-10\% mannitol solution instead of the $\mathrm{MnCl}_{2}$ solution (66-69).

\subsubsection{Hyperosmolar Mannitol Injection Through the External Carotid Artery}

1. Anesthesia (e.g., isoflurane, urethane or $\alpha$-chloralose)

2. Tape

3. Hair clipper (Note 1)

4. Surgical tools (blade with holder, hemostat, forceps, scissors etc.)

5. Microvascular clips

6. Disinfecting solutions (e.g., betadine, chlorhexidine, alcohol)

7. Polyethylene tubing PE-50, thinned to an outer diameter of $\sim 0.4 \mathrm{~mm}$ (Note 2 )

8. PE90 tube attached to the hub of a needle

9. 6-0 nylon suture

10. Mannitol solution (20\%)

11. Small metal laryngoscope

12. Muscular blocking agent (pancuronium bromide or gallamine triethiodide)

\footnotetext{
${ }^{1}$ For fur trimming in the rat, a conventional rodent hair clipper can be used. For the mouse, it is recommended to use small sharp scissors. Slightly pull on the skin in the opposite direction of the fur growth and then cut the hair as close as possible to the skin, taking care not to injure the skin in the process.

${ }^{2}$ It is necessary to use a "thinned out" PE50 tube as opposed to a smaller tube such as PE10. Use of PE10 tubing may not allow successful contrast agent injection because of high back pressure.
} 
13. Ventilator

\subsubsection{Intraperitoneal $\mathrm{MnCl}_{2}-$ Visual and Auditory Activation}

1. $\mathrm{MnCl}_{2}$ as a source of $\mathrm{Mn}^{2+}$ (66 mg/kg in saline - for intraperitoneal injections) (48, 70).

2. 1-ml syringe.

3. For auditory activation studies: auditory isolation box enabled for auditory stimulation with the addition of a sound synthesizer, audio amplifier, and speakers.

4. For visual activation studies: visual stimulation box consisting of four walls made up of 14-inch computer screens. Remaining areas consist of black-painted wood protected by aluminum mesh.

5. Anesthesia (isoflurane or urethane).

\subsubsection{Intranasal $\mathrm{MnCl}_{2}$ - Olfactory System Activation}

1. $\mathrm{MnCl}_{2}$ as a source of $\mathrm{Mn}^{2+}\left(10 \mathrm{mM}\right.$ in $\mathrm{H}_{2} \mathrm{O}$ - for intranasal administration of $7 \mu \mathrm{l} /$ naris or $1.5 \mathrm{M}$ in $\mathrm{H}_{2} \mathrm{O}$ for aerosolized $\mathrm{Mn}^{2+}$ administration with a vaporizer) (52, 61)

2. Pipette $-10 \mu \mathrm{l}$

3. Anesthesia (e.g., isoflurane, urethane)

4. Heating pad

5. Odorant for olfactory stimulation (e.g., 1:100 amyl acetate, 1:10 octanal, 1:10 carvone etc.)

6. Vaporizer

7. Fume hood

\subsection{Tract Tracing}

\subsubsection{Tract Tracing - Visual System}

1. $\mathrm{MnCl}_{2}$ as a source of $\mathrm{Mn}^{2+}\left(1 \mathrm{M}\right.$ in $\mathrm{H}_{2} \mathrm{O}$ - for intravitreal injections) $(36,62)$

2. 27-gauge needle

3. Polyethylene tubing $(0.4 \mathrm{~mm}$ diameter $)$

4. A 5- $\mu 1$ Hamilton syringe

5. Anesthesia (isoflurane or ketamine/xylazine combination or pentobarbital sodium, see Note 11)

6. Heating pad

7. Dissecting microscope

\subsubsection{Tract Tracing - Olfactory System}

1. $\mathrm{MnCl}_{2}$ as a source of $\mathrm{Mn}^{2+}\left(3.79 \mathrm{M}\right.$ in $\mathrm{H}_{2} \mathrm{O}-$ for intranasal administration) (61, $65)$

\footnotetext{
${ }^{11}$ Sodium pentobarbital dose: $50 \mathrm{mg} / \mathrm{kg}$ intraperitoneal injection. Ketamine/xylazine combination dose: $7.5 \mathrm{mg} / \mathrm{kg}$ ketamine with 5 $\mathrm{mg} / \mathrm{kg}$ xylazine.
} 
2. Pipette $-2 \mu \mathrm{l}$ or $10 \mu \mathrm{l}$

3. Anesthesia (e.g., isoflurane)

4. Heating pad

\subsubsection{Tract Tracing - Deep Brain Structures}

1. $\mathrm{MnCl}_{2}$ as a source of $\mathrm{Mn}^{2+}\left(5 \mathrm{mM}\right.$ in $\mathrm{H}_{2} \mathrm{O}-$ for intracranial injections) $(36,63,71$, 72)

2. Anesthesia (e.g., ketamine/xylazine combination as a pre-operative followed by $2 \%$ isoflurane for maintenance)

3. Surgical tools (blade with holder, hemostat, forceps, scissors etc.)

4. Disinfecting solution (chlorhexidine, betadine, alcohol)

5. Small sharp scissors and/or rodent hair clipper

6. Small drill with associated bits (similar to a dental drill)

7. 6-0 nylon suture

8. Mouse/rat brain atlas

9. Capillary tube puller

10. Quartz capillary tubes with filament

11. Surgical area including stereotaxic holder, dissecting microscope and gaseous anesthesia line

12. Surgical tool sterilizer (e.g., glass beads electric sterilizer)

13. Picospritzer with holder and push/pull options (to fill injection needles and subsequently inject solution out of them)

14. Heating pad

15. Sterile cotton swabs

16. Eye ointment

17. Leveling tool (small fork-shaped metallic tool that can be used to ascertain $2 \mathrm{D}$ horizontal leveling of the mouse/rat head in the stereotaxic holder)

18. Calibrated volume gauge (Note 3 )

\section{Methods}

\subsection{Anatomical Contrast Enhancement}

Anatomical contrast enhancement by systemic $\mathrm{Mn}^{2+}$ injection has been studied in rodents $(38-40,43,44)$, birds $(57,58)$, and primates $(54,55)$. The methods presented here are specifically designed for rat brain visualization based upon work developed in Koretsky's laboratory (44). The following methods can be adapted for use with any organism, provided reasonable optimization is conducted on the organism of interest as well as magnetic field strength.

\footnotetext{
${ }^{3}$ To construct a calibrated volume gauge, use Photoshop (or an equivalent drawing software) to draw a vertical line and add horizontal graduations to it that are separated by 1 pixel. Print the pattern on clear plastic (such as transparencies), cut it down to its proper size, and attach it to the injection syringe by means of a small piece of modeling clay. On such a scale and using 1-mm quartz capillary tubes, each graduation will correspond to $10 \mathrm{nl}$ of fluid.
} 
3.1.1. Preparation of the $\mathbf{M n C l}_{2}$ Solution-Different concentrations of $\mathrm{MnCl}_{2}$ can be used in systemic injections for positive contrast in $T_{1}$-weighted images $(37,44)$. Optimization, with regards to the animal model used, as well as available MRI hardware, should be performed for the best results. Also, when preparing $\mathrm{MnCl}_{2}$, care should be taken as to the tonicity and $\mathrm{pH}$ of the final solution. The body fluid has an osmolarity of 300 $\mathrm{mOsm} / \mathrm{l}$. One mole of $\mathrm{MnCl}_{2}$ is equivalent to $3 \mathrm{Osm}$. Therefore, concentrations in the range of $100 \mathrm{mM}$ should be used to insure proper tonicity when large amounts of $\mathrm{MnCl}_{2}$ are to be infused to the animals. When adjusting the $\mathrm{pH}$ of $\mathrm{MnCl}_{2}$ solution to a physiological $\mathrm{pH}$ of 7.4, bicine buffer, equilibrated with $\mathrm{NaOH}$, is a good buffer. Following are guidelines for the preparation of $100 \mathrm{mM} \mathrm{MnCl}_{2}$ at $\mathrm{pH}$ 7.4, suitable for imaging of rat cytoarchitecture by systemic $\mathrm{MnCl}_{2}$ injection.

1. Dissolve $1.63 \mathrm{~g}$ bicine ( $\mathrm{FW}=163.17$ ) in $100 \mathrm{ml}$ water to obtain a $100 \mathrm{mM}$ bicine solution.

2. Bring solution to $\mathrm{pH} 7.4$ using $\mathrm{NaOH}$.

3. Sterilize solution (either by autoclaving or by filtering).

4. Dissolve $98.95 \mathrm{mg}$ of $\mathrm{MnCl}_{2} \cdot 4 \mathrm{H}_{2} \mathrm{O}(\mathrm{FW}=197.91)$ into $5 \mathrm{ml}$ of sterile bicine solution. Depending on the weight of the animals used, 2-4 $\mathrm{ml}$ will be enough for imaging one animal; increase the volume of solution according to the number of animals to be imaged.

3.1.2. Intraperitoneal $\mathrm{MnCl}_{2}$ Injection-Systemic administration of $\mathrm{MnCl}_{2}$ by intraperitoneal injection consists of one injection of $100 \mathrm{mM} \mathrm{MnCl}_{2}$ at a dose of $66 \mathrm{mg} / \mathrm{kg}$. Imaging can be performed as early as $3 \mathrm{~h}$ and up to $24 \mathrm{~h}$ post-injection.

\subsubsection{Setting Up a Tail Vein Line}

1. Anesthetize the rat with $4 \%$ isoflurane in $\mathrm{O}_{2}$ initially and then keep it anesthetized with $1.5-2 \%$ isoflurane using a facemask.

2. Using forceps, break the metallic part of the 27 -gauge needle away from its plastic base connector. Take care to avoid causing the needle to get blocked. Connect the metallic part of the needle to its plastic base using a piece of tubing long enough to allow you to comfortably place the connected syringe onto the pump.

3. Fill 1-ml syringe with sterile physiological saline and attach it to the needle/tubing combination.

4. Immerse the tail in warm water to dilate the tail vein.

5. Insert the tip of the needle into the vein; proper insertion is confirmed by the backflow of blood from the tail into the saline-filled attached tubing.

6. To fix the needle in proper place, first use tape over the tubing to loosely hold everything in place. Then, using the nylon suture, tie a knot around the tail/metallic part of the needle. The suture will not go through the skin.

7. Carefully remove the saline-filled syringe and replace it with a $\mathrm{MnCl}_{2}$ pre-filled syringe.

8. Place the $\mathrm{MnCl}_{2}$ syringe into the holder of the syringe pump and set the infusion rate to $1.8 \mathrm{ml} / \mathrm{h}$. Do not start the infusion yet. 


\subsection{4. $\mathrm{MnCl}_{2}$ Infusion}

1. Inject $0.01 \mathrm{mg} / \mathrm{kg}$ glycopyrrolate intramuscularly. Glycopyrrolate is a muscarinic cholinergic blocker used as a pre-anesthetic medication to diminish the risk of vagal inhibition to the heart.

2. Insert a rectal probe into the rat, and maintain the temperature at $37.5^{\circ} \mathrm{C}$ during the infusion using an animal-heating system (e.g., warming blanket or heated air).

3. Keep the anesthesia light during the infusion (0.5-1\% isoflurane).

4. The goal $\mathrm{MnCl}_{2}$ concentration is $175 \mathrm{mg} / \mathrm{kg}$, which amounts to approximately $2 \mathrm{ml}$ of total volume per animal (Note 4).

5. To avoid dehydration, inject sterile saline subcutaneously $(6.7 \mathrm{ml} / 100 \mathrm{~g})$ immediately and $6 \mathrm{~h}$ after the $\mathrm{MnCl}_{2}$ infusion.

6. Keep the animals under controlled temperature for up to $24 \mathrm{~h}$ post-infusion. It is normal for the animals to display lethargic behavior at the end of the $\mathrm{MnCl}_{2}$ infusion. Their behavior will gradually improve to normal by $24 \mathrm{~h}$ post-infusion.

\subsubsection{Animal Preparation for MRI}

1. Anesthetize rats with $4 \%$ isoflurane initially.

2. Intubate the animals and keep them ventilated with $1.5 \%$ isoflurane in $\mathrm{O}_{2}$ (see Section 3.2.1.1. for detailed intubation protocol).

3. Maintain body temperature at $37.5^{\circ} \mathrm{C}$ using an animal-heating system.

4. Monitor temperature, blood pressure, and respiration rate with a small animal physiological monitoring system.

5. Inject the animals with pancuronium bromide $(2.5 \mathrm{mg} / \mathrm{kg})$ intraperitoneally to suppress motion (an alternative neuromuscular blocking agent is gallamine triethiodide $80 \mathrm{mg} / \mathrm{kg}$ i.v.).

3.1.6. Imaging Parameters-It should be noted that imaging protocols and parameters will vary considerably depending on the field strength to be used. Reported below are the optimal imaging parameters for proton MRI on an $11.7 \mathrm{~T}$ magnet based upon the work done by Aoki et al (44). The following parameters can be used as a starting point; however, further optimization should be performed for different field strengths and imaging protocols.

Two-dimensional multi-slice multi-echo (MSME-2D)

Repetition time $(\mathrm{TR})=300 \mathrm{~ms}$

Echo time $(\mathrm{TE})=10.5 \mathrm{~ms}$

Matrix size $=256 \times 256$

Field of view $(\mathrm{FOV})=25.6 \times 25.6 \mathrm{~mm}$

Slice thickness $(\mathrm{ST})=1 \mathrm{~mm}$

Number of averages $(\mathrm{NEX})=8$

${ }^{4}$ Several different concentrations of $\mathrm{Mn}^{2+}$ have been used in systemic administration studies. Doses ranged from $6.6 \mathrm{mg} / \mathrm{kg}$ to 175 $\mathrm{mg} / \mathrm{kg}$. With the higher doses, temporary side effects may occur; however, those effects resolve completely within an hour of $\mathrm{MnCl}_{2}$ administration. Many experimental factors such as the concentration of $\mathrm{MnCl}_{2}$, the rate of infusion, the route of administration as well as the type, and level of anesthesia play a critical role in a successful $\mathrm{MnCl}_{2}$ administration. 
An inversion recovery sequence could be used to acquire $T_{1}$-weighted images as well. The parameters are as follows:

$$
\begin{aligned}
& \text { Inversion time }=1,100 \mathrm{~ms} \\
& \mathrm{TR}=4,000 \mathrm{~ms} \\
& \mathrm{TE}=11.2 \mathrm{~ms} \\
& \text { Matrix size }=512 \times 256 \\
& \text { FOV }=38.4 \times 19.2 \mathrm{~mm} \\
& \mathrm{ST}=1 \mathrm{~mm} \\
& \mathrm{NEX}=1 \\
& \text { Three-dimensional spin echo }(\mathrm{SE}-3 \mathrm{D}) \\
& \mathrm{TR}=250 \mathrm{~ms} \\
& \mathrm{TE}=7.3 \mathrm{~ms} \\
& \text { Matrix size }=256 \times 256 \times 128 \\
& \text { FOV }=19.2 \times 19.2 \times 9.6 \mathrm{~mm} \\
& \text { NEX }=2 \\
& \text { Total acquisition time }=273 \mathrm{~min}
\end{aligned}
$$

3.1.7. Expected Results-The expected results are an increase in positive contrast enhancement in the central nervous system (Fig. 7.1). The pattern of enhancement can be obtained over a wide range of $\mathrm{MnCl}_{2}$ concentrations, with regions of the brain lacking a blood brain barrier (BBB), such as the pituitary gland, exhibiting stronger enhancement at low doses. Regions with an intact BBB, such as the hippocampus and cortex show a dosedependent increase in contrast enhancement. Higher doses may even allow the detection of finer details of the neuroarchitecture, such as cortical laminae structure.

\subsection{AIM-MRI}

Activation-induced MRI (AIM) is essentially a $\mathrm{Mn}^{2+}$-based functional MRI paradigm. It was introduced in 1997 by Lin and Koretsky as a blood-flow independent alternative to functional MARI (fMRI) (2). This method is based on the following two essential properties of $\mathrm{Mn}^{2+}$ : (1) $\mathrm{Mn}^{2+}$ can enter the brain parenchyma from the blood via a disrupted (or leaky) blood brain barrier (BBB) (66) and (2) $\mathrm{Mn}^{2+}$ is a $\mathrm{Ca}^{2+}$ analog that can enter neurons via voltage-gated $\mathrm{Ca}^{2+}$ channels and accumulates in neurons in an activity-dependent manner $(30,73-75) . \mathrm{Mn}^{2+}$ ions cannot efficiently enter the brain parenchyma through an intact BBB (66). Some diffusion may occur at the blood/CSF interface in choroid plexuses, but the amount of $\mathrm{Mn}^{2+}$ entering the brain is minimal compared to the cases where the $\mathrm{BBB}$ is disrupted $(1,76,77)$. As a result, most AIM studies to date were performed in conjunction with BBB disruption (66). Some studies on the activation of the auditory $(48,78,79)$ and visual pathways $(70,80)$ following auditory and visual stimulation respectively were performed in mice without disruption of the BBB. Also, a subset of functional studies in the olfactory system, capitalized on the active entry of $\mathrm{Mn}^{2+}$ through $\mathrm{Ca}^{2+}$ channels and its trans-synaptic transport (61). These studies were a spin-off from tract-tracing studies and were also performed without BBB disruption.

Several groups have used this technique since 1997 with certain variations regarding the route of administration of $\mathrm{MnCl}_{2}$ as well as the paradigm followed to break the BBB. 
Protocols are presented here for intravenous or intraperitoneal $\mathrm{MnCl}_{2}$ administration with hyperosmolar mannitol injections and infusions to break the BBB. Protocols involving olfactory, visual, or auditory activation without BBB disruption are also presented.

3.2.1. Intravenous Infusion of $\mathbf{M n C l}_{2}$ with $\mathrm{BBB}$ Disruption-The protocol for preparing $\mathrm{MnCl}_{2}$ and setting up a tail vein line for intravenous $\mathrm{MnCl}_{2}$ infusion was described in Sections 3.1.1-3.1.3. Here, a protocol for disrupting the BBB in conjunction with $\mathrm{MnCl}_{2}$ infusion is described.

\subsubsection{Direct Oral/Tracheal Intubation for Artificial Ventilation (Note 5)}

1. Anesthetize the mouse/rat with an intraperitoneal injection of $\alpha$-chloralose and urethane combination (Note 6).

2. Upon lack of toe pinch reflex, place the animal in dorsal position on a pre-heated warming pad.

3. Tape the limbs down.

4. Pull the head back by placing 4-0 nylon behind the upper incisors.

5. Use a small metal laryngoscope to pull the lower jaw down and expose the tracheal opening.

6. Insert a $\sim 2-\mathrm{cm}$ long PE-90 tubing attached to the hub of a needle about $3 \mathrm{~mm}$ into the trachea. The tip of the tube should be beveled in the direction of the natural bend of the tubing to avoid any tissue damage during insertion (Note 7).

7. Attach the needle hub to a ventilator and set it to $80-100$ breaths/min. (Do not turn the ventilator on yet; this will occur when imaging begins.)

\subsubsection{Catheterization of the External Carotid Artery for Hyperosmolar Mannitol Injection}

1. While the animal is still in dorsal position from the previous step, shave the neck area with a hair clipper (for rats) or sharp small scissors (for mice) (Note 1).

2. Disinfect the operating field with betadine and $75 \%$ alcohol.

3. Make a vertical $5-\mathrm{cm}$ incision and expose the arteries.

4. Temporarily clamp the right common and internal carotids using the microvascular clamps.

5. Carefully insert the PE50 tubing into the external carotid artery through a small puncture in the retrograde direction (Note 8).

6. Secure the tubing in place with 6-0 nylon suture. Tighten the sutures around the tube very well to prevent any further bleeding from the artery.

7. Remove the microvascular clamps.

8. Sew the wound back roughly keeping the tubes well in place.

\footnotetext{
${ }^{5}$ An alternative to the direct oral intubation for artificial ventilation is the performance of a tracheotomy. This is however not recommended for most experimental paradigms as it adds more surgical trauma to the animal.

${ }_{\alpha} \alpha$-Chloralose/urethane combination dose: $25 \mathrm{mg} / \mathrm{kg} \alpha$-chloralose with $450 \mathrm{mg} / \mathrm{kg}$ urethane intraperitoneal injection.

${ }^{7}$ Once the tube is properly inserted into the tracheal opening, it is relatively stable. To avoid any possible dislodging of the tube, it can be secured with 6-0 surgical nylon sutures to the front incisors of the animal

${ }^{8}$ When the catheter is introduced in the external carotid artery, care should be taken to introduce it in the direction of the common carotid artery, so that blood flow to the inferior carotid artery remains undisturbed.
} 
9. The mouse is now ready to be placed in the magnet.

\subsubsection{Animal Preparation for MRI}

1. Place the animal in a suitable holder with bite bars.

2. Set up a tail vein line for $\mathrm{MnCl}_{2}$ infusion as described in Section 3.1.2 (Note 9).

3. Extend all tubing outside of the magnet room.

4. Maintain anesthesia with $2 \%$ isoflurane.

5. Inject the animal with pancuronium bromide $(2.5 \mathrm{mg} / \mathrm{kg})$ intraperitoneally to suppress motion (an alternative neuromuscular blocking agent is gallamine triethiodide $80 \mathrm{mg} / \mathrm{kg}$ i.v.).

6. Start the ventilator for artificial breathing ( $80-100$ breaths/min).

3.2.1.4. Experimental Protocol: Keeping in mind that there are several different variations of experimental protocols, a typical setting for AIM experiments is given below.

1. Acquire a series of baseline scans.

2. Start the $\mathrm{MnCl}_{2}$ infusion (typically infusions last about $1 \mathrm{~h}$ ). Care should be taken in selecting the concentration of $\mathrm{MnCl}_{2}$ for AIM studies. $\mathrm{MnCl}_{2}$ causes toxicity to the heart due to $\mathrm{Mn}^{2+}$ homology to $\mathrm{Ca}^{2+}$. A very common initial effect of $\mathrm{MnCl}_{2}$ is a drop in blood pressure that is typically recovered to normal within $10 \mathrm{~min}$. Therefore, the concentration of $\mathrm{MnCl}_{2}$ may not have drastic effects in long-term studies, but it does affect short-term studies such as AIM. A concentration of 0.2 $\mathrm{mmol} / \mathrm{kg}$ infused over an hour has been shown to work well.

3. About halfway through the infusion, inject a bolus of $25 \%$ mannitol $(5-7 \mathrm{ml} / \mathrm{kg})$ through the external carotid catheter. Keep the room temperature higher than $25^{\circ} \mathrm{C}$ and pre-warm all tubing and attachments related to the mannitol injection. This is necessary to prevent mannitol recrystallization and subsequent micro-infarcts (Note 10). Unilateral injection usually results in the opening of the BBB on the side of the injection, with the contralateral receiving less $\mathrm{Mn}^{2+}$. The inhomogeneous opening of the BBB is not very well understood, but modulating some factors such as dose of mannitol, injection rate, distance of the injection site from the artery, age of the animal etc. plays an important role in obtaining sufficient BBB disruption for suitable contrast achievement.

4. At the completion of the $\mathrm{MnCl}_{2}$ infusion, administer the activating signal specific for the AIM study at hand (pharmacological as well as behavioral stimuli have been described).

5. Begin $T_{1}$-weighted image acquisitions at different time intervals to measure activation of specific brain areas involved in your study.

3.2.1.5. Imaging Parameters: Different imaging paradigms are possible for nervous system activity measurements using MEMRI in conjunction with BBB disruption. The imaging parameters will depend on the area of interest, organism used, as well as magnetic field

\footnotetext{
${ }^{9}$ When administering $\mathrm{MnCl}_{2}$ systemically through the venous system, an alternative to the tail vein catheterization is femoral vein catheterization. Both techniques have been shown to be equally effective.

${ }^{10}$ Mannitol can recrystallize in solution and cause micro-infarcts to the animal. To minimize the occurrence of re-crystallization, use pre-warmed tools such as syringes, saline, tubing etc. at $45^{\circ} \mathrm{C}$. Flush the catheter with warm saline prior to mannitol administration and keep the room temperature above $25^{\circ} \mathrm{C}$. Additionally, a $0.22-\mu \mathrm{m}$ filter can be used and should be connected as close as possible to the external carotid artery.
} 
strength. Optimization with regards to all of these variables is required for best results. Following is an example of imaging parameters, excerpted from Weng et al (50), for imaging cortical activity in rats following whisker stimulation at 3T.

Multi-slice spin-echo sequence

$\mathrm{TR}=500 \mathrm{~ms}$

$\mathrm{TE}=10 \mathrm{~ms}$

In-plane resolution $=187 \mu \mathrm{m}$

$\mathrm{ST}=1.5 \mathrm{~mm}$

3.2.1.6. Expected Results: Depending upon the system under study, one can expect to detect increased signal enhancement in areas of the brain involved in the activity studied. For example, following whisker stimulation, Weng et al. observed signal enhancement in the right cortical barrels of the rat brain (Fig. 7.2) (50).

\subsubsection{Activation Studies Without BBB Disruption - Visual and Auditory Systems}

\subsubsection{Activation Studies in the Auditory System}

\subsubsection{1. $\mathrm{MnCl}_{2}$ Administration}

1. Administer $66 \mathrm{mg} / \mathrm{kg} \mathrm{MnCl}_{2}$ as an intraperitoneal injection.

2. Place the animals in normal isolation cages with free access to food and water.

3. Place the isolation cage (with the animal in it) inside an auditory isolation box.

4. Subject the animals to different sound stimulation protocols over a period of $24 \mathrm{~h}$.

5. Upon completion of the auditory stimulation paradigm, initially anesthetize the animals with 5\% isoflurane followed by maintenance with $2 \%$ isoflurane and acquire $T_{1}$-weighted images.

6. A target region of interest for MEMRI quantification is in the auditory nuclei.

3.2.2.1.2. Imaging Parameters: Different imaging paradigms are possible for activity measurements from the auditory system using MEMRI. Following are optimal imaging parameters for the acquisition of $T_{1}$-weighted images of the mouse brain at 7T. These parameters are adapted from the work of Daniel Turnbull and associates (48) studying nerve activity in the auditory pathway of mice and are meant to be a starting guide. Further optimization is required depending upon the animal model used as well as the magnetic field strength.

$3 \mathrm{D}$ gradient echo pulse sequence

$\mathrm{TR}=50 \mathrm{~ms}$

$\mathrm{TE}=4 \mathrm{~ms}$

Flip angle $=65^{\circ}$

Total imaging time $=1 \mathrm{~h} 50$ min per mouse

This sequence yields a volumetric image set covering the whole brain, with an isotropic resolution of $100 \mu \mathrm{m}$

3.2.2.1.3. Expected Results: With the described auditory stimulation protocol combined with a systemic $\mathrm{MnCl}_{2}$ administration, one can expect to observe significant $\mathrm{Mn}^{2+}$ 
enhancement in structures of the auditory system, including the auditory nuclei in the brainstem and the thalamus (Fig. 7.3). Although the auditory cortex would also be expected to show enhancement, this particular protocol does not lead to signal enhancement in the auditory cortex, perhaps due to less $\mathrm{Mn}^{2+}$ reaching its remote location (48). Nonetheless, this technique is a very useful approach for studying neural activation in the auditory system and can be applied to different animal models of diseases involving the auditory system (e.g. Fig. 7.3).

\subsubsection{Activation Studies in the Visual System}

\subsubsection{1. $\mathrm{MnCl}_{2}$ Administration}

1. Prior to the start of the procedure, house the animals in darkness for $8-12 \mathrm{~h}$. All subsequent procedures and animal handling should be performed in darkness or under very dim red light.

2. Administer $66 \mathrm{mg} / \mathrm{kg} \mathrm{MnCl}_{2}$ as an intraperitoneal injection.

3. Place the animal in the stimulation chamber for $8 \mathrm{~h}$. Stimulation consists of a moving square wave (as opposed to constant diffuse light) to avoid habituation.

4. Upon completion of the stimulation paradigm, anesthetize the animals with isoflurane or urethane and acquire $T_{1}$-weighted MR images.

3.2.2.2. Imaging Parameters: Different imaging paradigms are possible for activity measurements from the visual system using MEMRI. Following are two sets of optimal imaging parameters for the acquisition of $T_{1}$-weighted images of the mouse or rat brain at 4.7T. These parameters are adapted from the work of Bruce Berkowitz and associates (70, 80) studying visual system activity in awake animals and are meant to be a starting guide. Further optimization is required depending on the animal model used as well as the magnetic field strength.

\subsection{Mouse Brain}

Adiabatic spin echo sequence

$\mathrm{TR}=350 \mathrm{~s}$

$\mathrm{TE}=16.7 \mathrm{~ms}$

Number of acquisitions $=16$

Sweep width $=61,728 \mathrm{~Hz}$

Matrix size $=512 \times 512$

$\mathrm{ST}=620 \mu \mathrm{m}$

$\mathrm{FOV}=12 \times 12 \mathrm{~mm}^{2}$

\subsection{Rat Brain}

Rapid Acquisition with Relaxation Enhancement (RARE) sequence

$\mathrm{TR}=330 \mathrm{~ms}$

$\mathrm{TE}=16.6 \mathrm{~ms}$

RARE factor $=8$

Number of acquisitions $=2$

Matrix size $=256 \times 256 \times 173$ 
$\mathrm{FOV}=3.84 \times 3.84 \mathrm{~cm}^{2}$

$\mathrm{ST}=150 \mu \mathrm{m}$

Time $=80 \mathrm{~min} / \mathrm{image}$

3.2.2.2.5. Expected Results: With the aforementioned protocol, one can expect to detect $\mathrm{Mn}^{2+}$ enhancement consistent with layer-specific visual cortex activity in awake and freemoving animals. Layers of a given cortical region respond differently to sensory stimulation and this MEMRI protocol appears to be sensitive enough to detect subtle changes in layerspecific activity $(70,80)$.

\subsubsection{Activation Studies Without BBB Disruption - Olfactory System}

3.2.3.1. $\mathrm{MnCl}_{2}$ Administration: Two current $\mathrm{Mn}^{2+}$ exposure modalities exist for activation studies from the olfactory system:

Intranasal administration of $\mathrm{MnCl}_{2}$

1

2

3

4

5

6

1

2

3

4
Anesthetize the animal with 5\% isoflurane.

Pipet $7 \mu \mathrm{l}$ of a $10 \mathrm{mM} \mathrm{MnCl}_{2}$ solution in each naris.

Allow the animal to recover on a heating pad.

Place the animal in a clean cage and drop $7 \mu$ of odorant solution in each of the four corners of the cage.

Allow odorant exposure for $20 \mathrm{~min}$.

Anesthetize the animal with 5\% isoflurane for imaging. Exposure to aerosolized $\mathrm{MnCl}_{2}$

Prepare a $1.5 \mathrm{M}$ solution of $\mathrm{MnCl}_{2}$ in $\mathrm{H}_{2} \mathrm{O}$.

Place the solution in the heating chamber of a humidifier or vaporizer. For experiments involving the exposure to an odor, mix the odor within the $\mathrm{MnCl}_{2}$ solution. Use a different humidifier for every odor used to avoid cross-contamination between experiments.

Place the vaporizer inside a fume hood to avoid exposure to $\mathrm{Mn}^{2+}$ vapors.

Animal exposure to the aerosolized $\mathrm{MnCl}_{2}$ with or without odor is performed on either awake or anesthetized animals and is done as follows:

- For awake animals: place the animal in the same plastic box housing the humidifier in the hood. Turn the humidifier on for $30 \mathrm{~min}$. Keep the mouse in the box for $1.5 \mathrm{~h}$ after the humidifier has been turned off. It is important not to open the box during that time because of possible exposure to the aerosolized $\mathrm{Mn}^{2+}$ still present.

- For anesthetized animals: anesthetize the animal with 20 $\mathrm{mg} / \mathrm{kg}$ urethane and secure it on top of the humidifier with a restraining device. The exposure paradigm involves two sequences of 5-min on and 5-min off, and then the animal is kept for $1.5 \mathrm{~h}$ in the chamber with the humidifier off. Again, it is important not to open the box during that time 
because of possible exposure to the aerosolized $\mathrm{Mn}^{2+}$ still present.

3.2.3.2. Imaging Parameters: Different field strengths will dictate different imaging parameters for best results. The following parameters are adapted from the work of Alan Koretsky and associates (52) for studying olfactory activation in mice at 11.7T. These imaging parameters are meant to be a starting guide; further optimization with regards to field strength and organism used is required.

$$
\begin{aligned}
& T_{1} \text {-weighted images acquired by a 3D RARE sequence } \\
& \mathrm{TR}=300 \mathrm{~ms} \\
& \mathrm{TE}=10 \mathrm{~ms} \\
& \text { Matrix size }=128 \times 128 \times 64 \\
& \text { RARE factor }=2
\end{aligned}
$$

Isotropic spatial resolution $=100 \mu \mathrm{m}$

3.2.3.3. Expected Results: The expected results from the activity-dependent olfactory tract tracing are a gradual increase in signal enhancement ranging from the olfactory epithelium to the olfactory bulbs. Signal enhancement will follow a region-specific enhancement depending on the stimulating odorant used (Fig. 7.4).

\subsection{Tract Tracing}

Tract tracing takes advantage of the following two properties of $\mathrm{Mn}^{2+}:$ (1) it is transported along neurons by microtubule-dependent axonal transport and (2) it can traverse synapses and reach second-order neurons leading to contrast enhancement of the whole neuronal system in question. Tract-tracing studies have been performed in several systems such as the visual and olfactory systems as well as from deep brain structures such as the hippocampus and amygdala.

\subsubsection{Tracing the Visual Pathway}

\subsubsection{1. $\mathrm{MnCl}_{2}$ Administration}

1. Anesthetize the animal initially with $5 \%$ isoflurane and then maintain it with $2 \%$ isoflurane.

2. Place the animal in the prone position on a heating pad to maintain body temperature

3. Gently detach the metallic piece of the 27-gauge needle from its plastic hub using forceps. Connect the metallic portion of the needle to the Hamilton syringe via a small piece of polyethylene tubing.

4. Insert the tip of the needle into the vitreous with the aid of a microscope. A good injection site is about $2 \mathrm{~mm}$ posterior to the dorsal limbus.

5. Inject $0.1 \mu \mathrm{l}$ of the $\mathrm{MnCl}_{2}$ solution over $5 \mathrm{~min}$. The volume injected can be gauged by the advancement of the meniscus in the polyethylene tube using the scale of the Hamilton syringe.

6. Leave the injection needle in the eye for at least $15 \mathrm{~min}$ and then withdraw it very slowly to minimize the loss of $\mathrm{MnCl}_{2}$ through leakage from the injection site. This waiting time is necessary to insure homogenous distribution of the $\mathrm{MnCl}_{2}$ inside the eye as well as for the intraocular pressure to reach equilibrium. 
7. Terminate anesthesia and return the animals to their cages.

8. Following the $\mathrm{MnCl}_{2}$ injection and prior to imaging, it is advised to check the integrity of the eyes. Successful injection can be ascertained by a bright-looking vitreal humor on a $T_{1}$-weighted image.

3.3.1.2. Imaging Parameters: Imaging parameters will vary depending on the animal model used as well as on the magnetic field strength. Following are the optimal imaging parameters used by Watanabe et al. to trace the visual pathway of rats at 2.35T (62). These parameters should be used as a starting guide and further optimization with regards to field strength performed for best results.

$T_{1}$-weighted 3D FLASH gradient echo sequence

$\mathrm{TR}=15 \mathrm{~ms}$

$\mathrm{TE}=4.2 \mathrm{~ms}$

Flip angle $=25^{\circ}$

$\mathrm{FOV}=50 \times 50 \times 16 \mathrm{~mm}$

Matrix size $=256 \times 256 \times 128$

$\mathrm{NEX}=8$

Acquisition time $=65.5 \mathrm{~min}$.

3.3.1.3. Expected Results: Signal enhancement is expected to be seen in the entire visual pathway, starting from the eye and extending to the superior colliculus. An example of such enhancement is illustrated in Fig. 7.5 (62).

\subsubsection{Tracing the Olfactory Pathway}

\subsubsection{1. $\mathrm{MnCl}_{2}$ Administration}

1. Anesthetize the animal with $5 \%$ isoflurane.

2. Hold animal in a vertical position by slightly pinching the hair in the back of the head.

3. Using a $10-\mu \mathrm{l}$ pipette, administer $2 \mu \mathrm{l}$ of a $3.9 \mathrm{M} \mathrm{MnCl}_{2}$ solution to each naris. The $2 \mu \mathrm{l}$ can be either administered as $2 \times 1 \mu \mathrm{l}$ or at once. It is normal to observe some bubbling from the nose following the nasal lavage.

4. Place the animal on a heating pad to accelerate recovery. Usually it only takes a few minutes for the animal to regain consciousness.

5. Return the animal to the housing cage.

6. Proper lavage can be ascertained by very dark-looking turbinates on a $T_{1}$-weighted image (due to $T_{2}$ effects of the concentrated $\mathrm{Mn}^{2+}$ solution).

3.3.2.2. Imaging Parameters: Based upon the work of Pautler et al (3), the optimal imaging parameters for tracing the olfactory system of the mouse at 7T are as follows:

$T_{1}$-weighted multi-slice spin echo sequence

$\mathrm{TR}=307 \mathrm{~ms}$

$\mathrm{TE}=12.7 \mathrm{~ms}$

$\mathrm{FOV}=2.5 \mathrm{~cm}$ 
$\mathrm{ST}=1 \mathrm{~mm}$

Matrix size $=128 \times 128$

Higher resolution 3D scans can be acquired using the following parameters:

$\mathrm{TR}=300 \mathrm{~ms}$

$\mathrm{TE}=8.7 \mathrm{~ms}$

$\mathrm{FOV}=2.5 \times 2.5 \times 2.5 \mathrm{~cm}$

Matrix size $=128 \times 128 \times 128$

3.3.2.3. Expected Results: The expected results are a positive contrast enhancement in the olfactory bulbs as well as the primary olfactory cortex as illustrated in Fig. 7.6 (3).

\subsubsection{Tracing of Deep Brain Structures}

\subsubsection{Injection Site Coordinates}

1. Identify the brain region you wish to inject.

2. Utilizing a stereotaxic brain atlas, determine the stereotaxic coordinates of the region of interest. This region will most likely encompass multiple slices. Be sure to choose the coordinates that correspond with the largest region in the structure of interest if possible. Additionally, it should be noted that the stereotaxic coordinates will vary based upon sex, age, and animal strain.

\subsubsection{Preparing the Injection Needle}

1. Using a pipet puller and a quartz capillary tube with filament, pull the tube to create the injection needle. A long, fine-tip needle is needed. Micropipette pullers use a size) velocity (determines the point at which the heat is turned off), delay (the time between deactivation of the laser and the application of a hard pull), and pull (final hard pull applied on the capillary tube) to create needles of different shapes and lengths. Keeping in mind that different pullers operate under different settings (same pullers may even differ depending on the type of filament they have), the following parameters are good starting points:

Heat=700; Filament=3; Velocity $=60$; Delay $=140 ;$ Pull $=175$

2. Using fine forceps, gently break the tip of the needle to open it (the needle comes out sealed from the puller).

3. Place the needle in the picospritzer holder.

4. Set the picospritzer to the "pull" option and slowly fill the needle with the $\mathrm{MnCl}_{2}$ solution.

5. Set the prepared needle aside and proceed to preparing the animal for surgery.

6. It is advisable to pull and fill several needles, in case one breaks during the surgery. Store the filled needles in a humidified chamber to prevent crystallization of the $\mathrm{MnCl}_{2}$ solution.

\subsubsection{Surgery}

1. Anesthetize the animal with pentobarbital sodium or ketamine/xylazine combination (Note 11). 
2. Upon lack of toe pinch reflex, place the animal on a warming blanket and clip the hair on the back of the head (the area extending from between the ears to the start of the back) (see Note 1).

3. Fix the animal's head in a stereotaxic holder complete with a bite bar and cheek/ear bars.

4. Maintain anesthesia with $2 \%$ isoflurane.

5. Clean the operating field with the disinfecting solution chlorhexidine alternating with sterile water (three times).

6. Make a vertical incision extending from the nose to the start of the back; hold the skin open with hemostats.

7. With the help of the leveling tool and the microscope, make sure that the head is leveled properly both in the longitudinal and horizontal directions.

8. Using the stereotaxic device, determine the coordinates of your animal's Bregma.

9. Calculate the placement of your region of interest with regards to the Bregma coordinates. For example, if your region of interest mesolateral position was -4.2 and your animal's Bregma was located at the mesolateral coordinate of 34.6, then you will need to place your holder at the 30.4 position (34.6-4.2). The same type of calculation applies to the other coordinates.

10. Mark the $2 \mathrm{D}$ location of the injection site by making a small scrape with the tip of a 27-gauge needle.

11. Begin drilling carefully at that location. Be sure to only drill a hole into the skull (e.g., mouse skull is less than $1 \mathrm{~mm}$ thick). The drill bit should not go through the dura or brain tissue.

12. Attach the volume gauge to the pre-filled needle with a small piece of modeling clay.

13. Lower the filled needle into the drilled hole. Carefully let the tip of the needle pierce the dura. Keep lowering until you reach the pre-calculated depth coordinate of your region of interest.

14. Adjust the microscope focus on the gauge so that the injected volume can be monitored.

15. Set the injection pressure to $20 \mathrm{psi}$ approximately and begin with an injection time of $5 \mathrm{~ms}$. Gradually increase the injection time until you see the meniscus slightly move within the needle.

16. Inject the full volume using this setting. Typically $10-20 \mathrm{nl}$ is suitable for tracing from deep brain structures (see Note 3).

17. Leave the injection needle in for at least $5 \mathrm{~min}$ and then withdraw it very slowly. This step is necessary to avoid the backflow of $\mathrm{MnCl}_{2}$ through the injection canal.

18. Place a few drops of analgesic such as bupivicaine just underneath the scalp and away from the drill hole and then suture the wound with 6-0 nylon suture.

3.3.3.4. Imaging Parameters: Different imaging paradigms are possible for tracing from deep brain structures following setereotaxic $\mathrm{Mn}^{2+}$ injections. Both 2D and 3D protocols can be used (3D recommended). Following are optimal imaging parameters for the acquisition of $T_{1}$-weighted images of the guinea pig brain at $3 \mathrm{~T}$. These parameters are adapted from the work of Lee et al. for tracing the auditory pathway in guinea pigs (63) and are meant to be a 
starting guide. Further optimization is required depending on the organism used as well as on the magnetic field strength.

Two-dimensional spin echo sequence

$\mathrm{TR}=450 \mathrm{~ms}$

$\mathrm{TE}=13 \mathrm{~ms}$

Matrix size $=256 \times 256$

$\mathrm{FOV}=50 \times 50 \mathrm{~mm}$

$\mathrm{ST}=1.5 \mathrm{~mm}$ (with a slice gap of $0.1 \mathrm{~mm}$ )

$\mathrm{NEX}=10$

Three-dimensional gradient echo sequence

$\mathrm{TR}=10.2 \mathrm{~ms}$

$\mathrm{TE}=2.5 \mathrm{~ms}$

Flip angle $=30^{\circ}$

Matrix size $=256 \times 256 \times 128$

$\mathrm{FOV}=50 \times 50 \times 50 \mathrm{~mm}$

NEX $=7$

3.3.3.5. Expected Results: The expected results are a multi-synaptic tract tracing to all structures involved in the system that is peripherally injected. For example, following injection of $\mathrm{Mn}^{2+}$ to the cochlea (63), signal enhancement can be observed in the entire auditory pathway, including the cochlear nucleus, the lateral lemniscus, the inferior colliculus, the medial geniculate nucleus, and the trigeminal tract (Fig. 7.7).

\subsection{Concluding Remarks}

As delineated by the multitude of techniques described in this chapter, MEMRI is undoubtedly a very useful technique for the study of the brain anatomy and activity. Perhaps the most important aspect of MEMRI is that it is minimally invasive and offers the possibility of longitudinal studies. This is of utmost importance for efficient diagnosis and understanding of disease states. Although MEMRI has been quite developed and refined in several organ systems $(37,53)$ of various animal models such as rodents $(3,44,81,82)$, song-birds $(56-58)$, and non-human primates $(55,83)$, its use in humans is still almost nonexistent. To date, $\mathrm{Mn}^{2+}$ has been approved for clinical imaging only in its chelated form (84). This is primarily due to the toxicity associated with a high concentration of free $\mathrm{Mn}^{2+}$ ions. High concentrations of $\mathrm{Mn}^{2+}$ have been shown to cause acute cardiovascular depression (85) as well as neurodegenerative damage to the nervous system (4). Many efforts are currently focused on developing $\mathrm{Mn}^{2+}$ contrast agents lacking the traditional side effects of $\mathrm{Mn}^{2+}$. One such agent, available from Eagle Vision Pharmaceuticals, consists of free $\mathrm{Mn}^{2+}$ ions formulated with $\mathrm{Ca}^{2+}$ to override the transient effect of $\mathrm{Mn}^{2+}$ as a $\mathrm{Ca}^{2+}$ competitive inhibitor. This agent is currently used in dogs and pigs for cardiac $(86,87)$ as well as for vascular imaging (88). The development of such agent shows promise for the imminent use of $\mathrm{Mn}^{2+}$ as a clinical contrast agent for cardiac and brain imaging. 


\section{References}

1. London RE, Toney G, Gabel SA, Funk A. Magnetic resonance imaging studies of the brains of anesthetized rats treated with manganese chloride. Brain Res Bull. 1989; 23:229-235. [PubMed: 2819480]

2. Lin YJ, Koretsky AP. Manganese ion enhances T1-weighted MRI during brain activation: An approach to direct imaging of brain function. Magn Reson Med. 1997; 38:378-388. [PubMed: 9339438]

3. Pautler RG, Silva AC, Koretsky AP. In vivo neuronal tract tracing using manganese-enhanced magnetic resonance imaging. Magn Reson Med. 1998; 40(5):740-748. [PubMed: 9797158]

4. Santamaria AB. Manganese exposure, essentiality \& toxicity. Indian J Med Res. 2008; 128:484 500. [PubMed: 19106442]

5. Hurley, LS.; Keen, CL. Manganese. In: Underwood, E.; Mertz, W., editors. Trace Elements in Human Health and Animal Nutrition. New York, NY: Academic Press; 1987. p. 185-225.

6. Zwingmann C, Leibfritz D, Hazell AS. Brain energy metabolism in a subacute rat model of manganese neurotoxicity: An ex vivo nuclear magnetic resonance study using [1-13 c]glucose. Neurotoxicology. 2004; 25:573-587. [PubMed: 15183011]

7. Patchett ML, Daniel RM, Morgan HW. Characterisation of arginase from the extreme thermophile 'Bacillus caldovelox'. Biochim Biophys Acta. 1991; 1077:291-298. [PubMed: 2029528]

8. Wedler FC, Denman RB. Glutamine synthetase: The major Mn(II) enzyme in mammalian brain. Curr Top Cell Regul. 1984; 24:153-169. [PubMed: 6149889]

9. Keen, C. Nutritional and toxicological aspects of manganese intake: an overview. In: Mertz, W.; Abernathy, C.; Olin, S., editors. Risk Assessment of Essential Elements. Washington, DC: ILSI Press; 1994.

10. Strause LG, Hegenauer J, Saltman P, Cone R, Resnick D. Effects of long-term dietary manganese and copper deficiency on rat skeleton. J Nutr. 1986; 116:135-141. [PubMed: 3944652]

11. Friedman BJ, Freeland-Graves JH, Bales CW, Behmardi F, Shorey-Kutschke RL, Willis RA, Crosby JB, Trickett PC, Houston SD. Manganese balance and clinical observations in young men fed a manganese-deficient diet. J Nutr. 1987; 117:133-143. [PubMed: 3819860]

12. Venugopal, B.; Luckey, T. Metal Toxicity in Mammals. Chemical Toxicity of Metals and Metalloids. New York, NY: Plenum Press; 1978.

13. Aschner M, Guilarte TR, Schneider JS, Zheng W. Manganese: Recent advances in understanding its transport and neurotoxicity. Toxicol Appl Pharmacol. 2007; 221:131-147. [PubMed: 17466353]

14. Crossgrove J, Zheng W. Manganese toxicity upon overexposure. NMR Biomed. 2004; 17:544553. [PubMed: 15617053]

15. Sloot WN, Gramsbergen JB. Axonal transport of manganese and its relevance to selective neurotoxicity in the rat basal ganglia. Brain Res. 1994; 657:124-132. [PubMed: 7820609]

16. Takeda A, Kodama Y, Ishiwatari S, Okada S. Manganese transport in the neural circuit of rat CNS. Brain Res Bull. 1998; 45:149-152. [PubMed: 9443831]

17. Tjälve H, Mejàre C, Borg-Neczak K. Uptake and transport of manganese in primary and secondary olfactory neurones in pike. Pharmacol Toxicol. 1995; 77:23-31. [PubMed: 8532608]

18. Takeda A, Ishiwatari S, Okada S. In vivo stimulation-induced release of manganese in rat amygdala. Brain Res. 1998; 811:147-151. [PubMed: 9804933]

19. Barbeau A. Manganese and extrapyramidal disorders (a critical review and tribute to dr. George C. Cotzias). Neurotoxicology. 1984; 5:13-35. [PubMed: 6538948]

20. Mena I, Marin O, Fuenzalida S, Cotzias GC. Chronic manganese poisoning. Clinical picture and manganese turnover. Neurology. 1967; 17:128-136. [PubMed: 6066873]

21. Finley JW. Manganese uptake and release by cultured human hepatocarcinoma (hep-G2) cells. Biol Trace Elem Res. 1998; 64:101-118. [PubMed: 9845466]

22. Kerper LE, Hinkle PM. Cellular uptake of lead is activated by depletion of intracellular calcium stores. J Biol Chem. 1997; 272:8346-8352. [PubMed: 9079658] 
23. Mason MJ, Mayer B, Hymel LJ. Inhibition of $\mathrm{Ca}^{2+}$ transport pathways in thymic lymphocytes by econazole, miconazole, and SKF 96365. Am J Physiol. 1993; 264:C654-C662. [PubMed: 8384787]

24. Murphy VA, Smith QR, Rapoport SI. Saturable transport of ca into CSF in chronic hypo- and hypercalcemia. J Neurosci Res. 1991; 30:421-426. [PubMed: 1798059]

25. Takeda A. Manganese action in brain function. Brain Res Brain Res Rev. 2003; 41:79-87. [PubMed: 12505649]

26. Chance B. The energy-linked reaction of calcium with mitochondria. J Biol Chem. 1965; 240:2729-2748. [PubMed: 14304892]

27. Huang C, Cheng H, Lin K, Cheng J, Tsai J, Liao W, Fang Y, Jan C. Tamoxifen-induced [Ca $\left.{ }^{2+}\right] \mathrm{i}$ rise and apoptosis in corneal epithelial cells. Toxicology. 2009; 255:58-64. [PubMed: 18992300]

28. Tas PWL, Stössel C, Roewer N. Inhibition of the histamine-induced $\mathrm{Ca}^{2+}$ influx in primary human endothelial cells (HUVEC) by volatile anaesthetics. Eur J Anaesthesiol. 2008; 25:976-985. [PubMed: 18631421]

29. Merritt JE, Jacob R, Hallam TJ. Use of manganese to discriminate between calcium influx and mobilization from internal stores in stimulated human neutrophils. J Biol Chem. 1989; 264:15221527. [PubMed: 2536366]

30. Narita K, Kawasaki F, Kita H. Mn and Mg influxes through Ca channels of motor nerve terminals are prevented by verapamil in frogs. Brain Res. 1990; 510:289-295. [PubMed: 2158851]

31. Simpson PB, Challiss RA, Nahorski SR. Divalent cation entry in cultured rat cerebellar granule cells measured using $\mathrm{Mn}^{2+}$ quench of fura 2 fluorescence. Eur J Neurosci. 1995; 7:831-840. [PubMed: 7613620]

32. Cory DA, Schwartzentruber DJ, Mock BH. Ingested manganese chloride as a contrast agent for magnetic resonance imaging. Magn Reson Imaging. 1987; 5:65-70. [PubMed: 3586874]

33. Geraldes CF, Sherry AD, Brown RD, Koenig SH. Magnetic field dependence of solvent proton relaxation rates induced by $\mathrm{Gd}^{3+}$ and $\mathrm{Mn}^{2+}$ complexes of various polyaza macrocyclic ligands: implications for NMR imaging. Magn Reson Med. 1986; 3:242-250. [PubMed: 3086656]

34. Fornasiero D, Bellen JC, Baker RJ, Chatterton BE. Paramagnetic complexes of manganese(II), iron(III), and gadolinium(III) as contrast agents for magnetic resonance imaging. The influence of stability constants on the biodistribution of radioactive aminopolycarboxylate complexes. Invest Radiol. 1987; 22:322-327. [PubMed: 3583652]

35. Mendonça-Dias MH, Gaggelli E, Lauterbur PC. Paramagnetic contrast agents in nuclear magnetic resonance medical imaging. Semin Nucl Med. 1983; 13:364-376. [PubMed: 6359418]

36. Pautler RG. Biological applications of manganese-enhanced magnetic resonance imaging. Methods Mol Med. 2006; 124:365-386. [PubMed: 16506430]

37. Silva AC, Lee JH, Aoki I, Koretsky AP. Manganese-enhanced magnetic resonance imaging (MEMRI): Methodological and practical considerations. NMR Biomed. 2004; 17:532-543. [PubMed: 15617052]

38. Natt O, Watanabe T, Boretius S, Radulovic J, Frahm J, Michaelis T. High-resolution 3D MRI of mouse brain reveals small cerebral structures in vivo. J Neurosci Methods. 2002; 120:203-209. [PubMed: 12385770]

39. Watanabe T, Natt O, Boretius S, Frahm J, Michaelis T. In vivo 3D MRI staining of mouse brain after subcutaneous application of $\mathrm{MnCl} 2$. Magn Reson Med. 2002; 48:852-859. [PubMed: 12418000]

40. Watanabe T, Radulovic J, Spiess J, Natt O, Boretius S, Frahm J, Michaelis T. In vivo 3D MRI staining of the mouse hippocampal system using intracerebral injection of $\mathrm{MnCl} 2$. Neuroimage. 2004; 22:860-867. [PubMed: 15193616]

41. Watanabe T, Radulovic J, Boretius S, Frahm J, Michaelis T. Mapping of the habenulointerpeduncular pathway in living mice using manganese-enhanced 3D MRI. Magn Reson Imaging. 2006; 24:209-215. [PubMed: 16563949]

42. Bock NA, Paiva FF, Nascimento GC, Newman JD, Silva AC. Cerebrospinal fluid to brain transport of manganese in a non-human primate revealed by MRI. Brain Res. 2008; 1198:160 170. [PubMed: 18243167] 
43. Silva AC, Lee JH, Wu CW, Tucciarone J, Pelled G, Aoki I, Koretsky AP. Detection of cortical laminar architecture using manganese-enhanced MRI. J Neurosci Methods. 2008; 167:246-257. [PubMed: 17936913]

44. Aoki I, Wu YL, Silva AC, Lynch RM, Koretsky AP. In vivo detection of neuroarchitecture in the rodent brain using manganese-enhanced MRI. Neuroimage. 2004; 22:1046-1059. [PubMed: 15219577]

45. Deans AE, Wadghiri YZ, Berrios-Otero CA, Turnbull DH. Mn enhancement and respiratory gating for in utero MRI of the embryonic mouse central nervous system. Magn Reson Med. 2008; 59:1320-1328. [PubMed: 18506798]

46. Duong TQ, Silva AC, Lee SP, Kim SG. Functional MRI of calcium-dependent synaptic activity: Cross correlation with CBF and BOLD measurements. Magn Reson Med. 2000; 43:383-392. [PubMed: 10725881]

47. Aoki I, Tanaka C, Takegami T, Ebisu T, Umeda M, Fukunaga M, Fukuda K, Silva AC, Koretsky AP, Naruse S. Dynamic activity-induced manganese-dependent contrast magnetic resonance imaging (DAIM MRI). Magn Reson Med. 2002; 48:927-933. [PubMed: 12465100]

48. Yu X, Wadghiri YZ, Sanes DH, Turnbull DH. In vivo auditory brain mapping in mice with Mnenhanced MRI. Nat Neurosci. 2005; 8(7):961-968. [PubMed: 15924136]

49. Parkinson JRC, Chaudhri OB, Bell JD. Imaging appetite-regulating pathways in the central nervous system using manganese-enhanced magnetic resonance imaging. Neuroendocrinology. 2009; 89:121-130. [PubMed: 18849597]

50. Weng J, Chen J, Yang P, Tseng WI. Functional mapping of rat barrel activation following whisker stimulation using activity-induced manganese-dependent contrast. Neuroimage. 2007; 36:1179_ 1188. [PubMed: 17537649]

51. Lu H, Xi Z, Gitajn L, Rea W, Yang Y, Stein EA. Cocaine-induced brain activation detected by dynamic manganese-enhanced magnetic resonance imaging (MEMRI). Proc Natl Acad Sci USA. 2007; 104:2489-2494. [PubMed: 17287361]

52. Chuang K, Lee JH, Silva AC, Belluscio L, Koretsky AP. Manganese enhanced MRI reveals functional circuitry in response to odorant stimuli. Neuroimage. 2009; 44:363-372. [PubMed: 18848997]

53. Wendland MF. Applications of manganese-enhanced magnetic resonance imaging (MEMRI) to imaging of the heart. NMR Biomed. 2004; 17:581-594. [PubMed: 15761947]

54. Murayama Y, Weber B, Saleem KS, Augath M, Logothetis NK. Tracing neural circuits in vivo with Mn-enhanced MRI. Magn Reson Imaging. 2006; 24:349-358. [PubMed: 16677940]

55. Saleem KS, Pauls JM, Augath M, Trinath T, Prause BA, Hashikawa T, Logothetis NK. Magnetic resonance imaging of neuronal connections in the macaque monkey. Neuron. 2002; 34:685-700. [PubMed: 12062017]

56. Tindemans I, Verhoye M, Balthazart J, Van Der Linden A. In vivo dynamic ME-MRI reveals differential functional responses of RA- and area X-projecting neurons in the HVC of canaries exposed to con-specific song. Eur J Neurosci. 2003; 18:3352-3360. [PubMed: 14686908]

57. Van der Linden A, Verhoye M, Van Meir V, Tindemans I, Eens M, Absil P, Balthazart J. In vivo manganese-enhanced magnetic resonance imaging reveals connections and functional properties of the songbird vocal control system. Neuroscience. 2002; 112:467-474. [PubMed: 12044464]

58. Van der Linden A, Van Meir V, Tindemans I, Verhoye M, Balthazart J. Applications of manganese-enhanced magnetic resonance imaging (MEMRI) to image brain plasticity in song birds. NMR Biomed. 2004; 17:602-612. [PubMed: 15761949]

59. Van Meir V, Verhoye M, Absil P, Eens M, Balthazart J, Van der Linden A. Differential effects of testosterone on neuronal populations and their connections in a sensorimotor brain nucleus controlling song production in songbirds: A manganese enhanced-magnetic resonance imaging study. Neuroimage. 2004; 21:914-923. [PubMed: 15006658]

60. Pautler RG. In vivo, trans-synaptic tract-tracing utilizing manganese-enhanced magnetic resonance imaging (MEMRI). NMR Biomed. 2004; 17:595-601. [PubMed: 15761948]

61. Pautler RG, Koretsky AP. Tracing odor-induced activation in the olfactory bulbs of mice using manganese-enhanced magnetic resonance imaging. Neuroimage. 2002; 16:441-448. [PubMed: 12030829] 
62. Watanabe T, Michaelis T, Frahm J. Mapping of retinal projections in the living rat using highresolution 3D gradient-echo MRI with $\mathrm{Mn}^{2+}$-induced contrast. Magn Reson Med. 2001; 46(3): 424-429. [PubMed: 11550231]

63. Lee J, Park J, Lee J, Bae S, Lee S, Jung J, Kim M, Lee J, Woo S, Chang Y. Manganese-enhanced auditory tract-tracing MRI with cochlear injection. Magn Reson Imaging. 2007; 25:652-656. [PubMed: 17540276]

64. Serrano F, Deshazer M, Smith KDB, Ananta JS, Wilson LJ, Pautler RG. Assessing transneuronal dysfunction utilizing manganese-enhanced MRI (MEMRI). Magn Reson Med. 2008; 60:169-175. [PubMed: 18581360]

65. Smith KDB, Kallhoff V, Zheng H, Pautler RG. In vivo axonal transport rates decrease in a mouse model of alzheimer's disease. Neuroimage. 2007; 35:1401-1408. [PubMed: 17369054]

66. Aoki I, Naruse S, Tanaka C. Manganese-enhanced magnetic resonance imaging (MEMRI) of brain activity and applications to early detection of brain ischemia. NMR Biomed. 2004; 17:569-580. [PubMed: 15617055]

67. Kidoguchi K, Tamaki M, Mizobe T, Koyama J, Kondoh T, Kohmura E, Sakurai T, Yokono K, Umetani K. In vivo X-ray angiography in the mouse brain using synchrotron radiation. Stroke. 2006; 37:1856-1861. [PubMed: 16741182]

68. Zhao X, Wu N, Deng M, Yin Y, Zhou J, Fang Y, Huang L. An improved method of left ventricular catheterization in rats. Physiol Meas. 2006; 27:N27-N33. [PubMed: 16603795]

69. Brown RH, Walters DM, Greenberg RS, Mitzner W. A method of endotracheal intubation and pulmonary functional assessment for repeated studies in mice. J Appl Physiol. 1999; 87:23622365. [PubMed: 10601190]

70. Bissig D, Berkowitz BA. Manganese-enhanced MRI of layer-specific activity in the visual cortex from awake and free-moving rats. Neuroimage. 2009; 44:627-635. [PubMed: 19015035]

71. Pautler RG, Mongeau R, Jacobs RE. In vivo trans-synaptic tract tracing from the murine striatum and amygdala utilizing manganese enhanced MRI (MEMRI). Magn Reson Med. 2003; 50:33-39. [PubMed: 12815676]

72. Watanabe T, Frahm J, Michaelis T. Functional mapping of neural pathways in rodent brain in vivo using manganese-enhanced three-dimensional magnetic resonance imaging. NMR Biomed. 2004; 17:554-568. [PubMed: 15617054]

73. Burnett KR, Goldstein EJ, Wolf GL, Sen S, Mamourian AC. The oral administration of MnCl2: A potential alternative to IV injection for tissue contrast enhancement in magnetic resonance imaging. Magn Reson Imaging. 1984; 2:307-314. [PubMed: 6530933]

74. Kita H, Narita K, Van der Kloot W. Tetanic stimulation increases the frequency of miniature endplate potentials at the frog neuromuscular junction in $\mathrm{Mn}^{2+}, \mathrm{CO}^{2+}$, and $\mathrm{Ni}^{2+}$-saline solutions. Brain Res. 1981; 205:111-121. [PubMed: 6258705]

75. Drapeau P, Nachshen DA. Manganese fluxes and manganese-dependent neurotrans-mitter release in presynaptic nerve endings isolated from rat brain. J Physiol (Lond). 1984; 348:493-510. [PubMed: 6325673]

76. Rabin O, Hegedus L, Bourre JM, Smith QR. Rapid brain uptake of manganese(II) across the blood-brain barrier. J Neurochem. 1993; 61:509-517. [PubMed: 7687654]

77. Murphy VA, Rosenberg JM, Smith QR, Rapoport SI. Elevation of brain manganese in calciumdeficient rats. Neurotoxicology. 1991; 12:255-263. [PubMed: 1956585]

78. Yu X, Sanes DH, Aristizabal O, Wadghiri YZ, Turnbull DH. Large-scale reorganization of the tonotopic map in mouse auditory midbrain revealed by MRI. Proc Natl Acad Sci USA. 2007; 104:12193-12198. [PubMed: 17620614]

79. Yu X, Zou J, Babb JS, Johnson G, Sanes DH, Turnbull DH. Statistical mapping of sound-evoked activity in the mouse auditory midbrain using Mn-enhanced MRI. Neuroimage. 2008; 39:223-230. [PubMed: 17919926]

80. Berkowitz BA, Gradianu M, Bissig D, Kern TS, Roberts R. Retinal ion regulation in a mouse model of diabetic retinopathy: Natural history and the effect of $\mathrm{Cu} / \mathrm{Zn}$ superoxide dismutase overexpression. Invest Ophthalmol Vis Sci. 2009; 50:2351-2358. [PubMed: 19074809]

81. Hu TC, Pautler RG, MacGowan GA, Koretsky AP. Manganese-enhanced MRI of mouse heart during changes in inotropy. Magn Reson Med. 2001; 46:884-890. [PubMed: 11675639] 
82. Lee JH, Silva AC, Merkle H, Koretsky AP. Manganese-enhanced magnetic resonance imaging of mouse brain after systemic administration of $\mathrm{MnCl} 2$ : Dose-dependent and temporal evolution of T1 contrast. Magn Reson Med. 2005; 53:640-648. [PubMed: 15723400]

83. Bock, NA.; Kocharyan, A.; Silva, AC. [Accessed July 21, 2009] Manganese-enhanced MRI visualizes V1 in the non-human primate visual cortex. NMR Biomed. 2009. Available at: http://www.ncbi.nlm.nih.gov/pubmed/19322808

84. Federle MP, Chezmar JL, Rubin DL, Weinreb JC, Freeny PC, Semelka RC, Brown JJ, Borello JA, Lee JK, Mattrey R, Dachman AH, Saini S, Harmon B, Fenstermacher M, Pelsang RE, Harms SE, Mitchell DG, Halford HH, Anderson MW, Johnson CD, Francis IR, Bova JG, Kenney PJ, Klippenstein DL, Foster GS, Turner DA. Safety and efficacy of mangafodipir trisodium (MnDPDP) injection for hepatic MRI in adults: Results of the U.S. multicenter phase III clinical trials (safety). J Magn Reson Imaging. 2000; 12:186-197. [PubMed: 10931579]

85. Wolf GL, Baum L. Cardiovascular toxicity and tissue proton T1 response to manganese injection in the dog and rabbit. AJR Am J Roentgenol. 1983; 141:193-197. [PubMed: 6305179]

86. Storey P, Chen Q, Li W, Seoane PR, Harnish PP, Fogelson L, Harris KR, Prasad PV. Magnetic resonance imaging of myocardial infarction using a manganese-based contrast agent (EVP 1001-1): Preliminary results in a dog model. J Magn Reson Imaging. 2006; 23:228-234. [PubMed: 16416440]

87. Storey P, Danias PG, Post M, Li W, Seoane PR, Harnish PP, Edelman RR, Prasad PV. Preliminary evaluation of EVP 1001-1: A new cardiac-specific magnetic resonance contrast agent with kinetics suitable for steady-state imaging of the ischemic heart. Invest Radiol. 2003; 38:642-652. [PubMed: 14501492]

88. Zuo CS, Seoane P, Lanigan T, Harnish P, Prasad PV, Storey P, Li W, Rofsky NM. T1 efficacy of EVP-ABD: A potential manganese-based MR contrast agent for hepatic vascular and tissue phase imaging. J Magn Reson Imaging. 2002; 16:668-675. [PubMed: 12451580] 

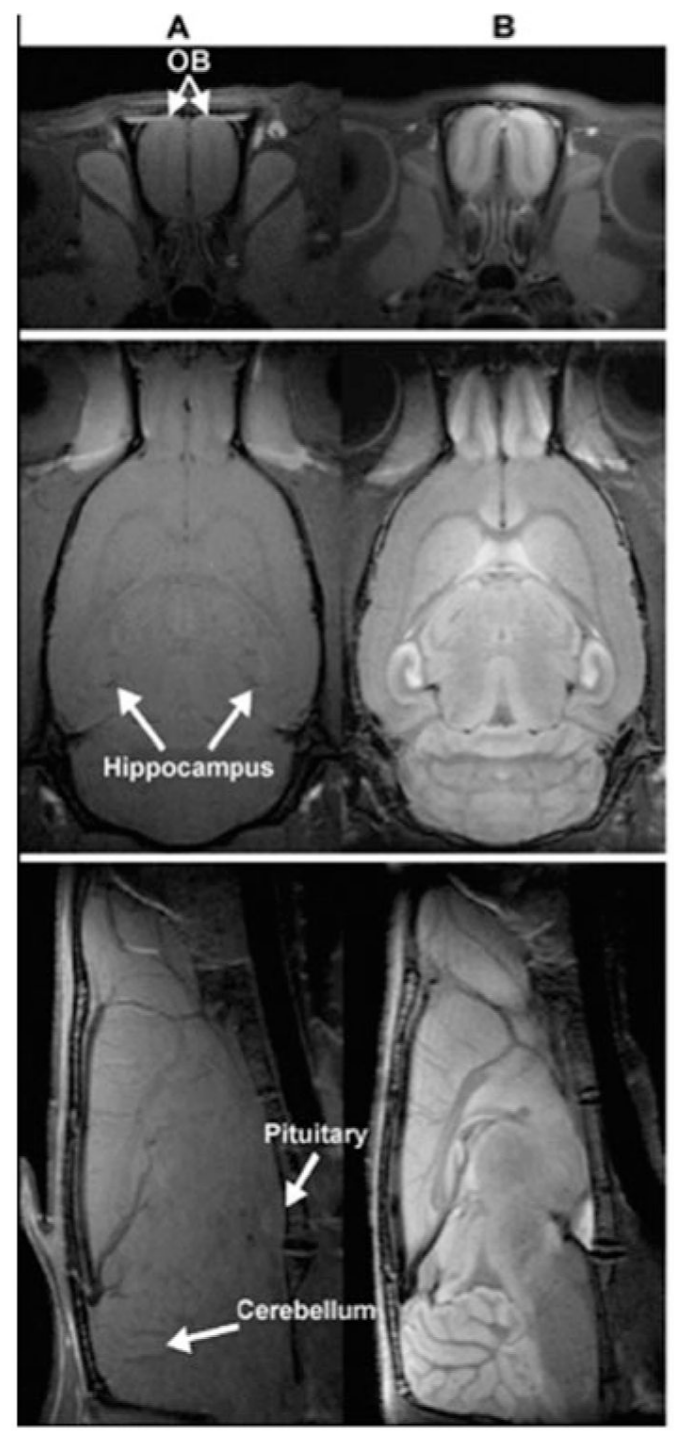

Fig. 7.1.

$T_{1}$-weighted MRI after systemic $\mathrm{MnCl}_{2}$ administration in the rat. $T_{1}$-weighted MRI of a control rat (column $A$ ) and a rat 1 day after IV infusion of $\mathrm{MnCl}_{2}$ solution (column B). Top row shows transverse slices at the level of the olfactory bulb (OB, Bregma: $+7 \mathrm{~mm})$. The middle row shows horizontal slices including the hippocampal formation (Bregma: $-6 \mathrm{~mm}$ ). The bottom row shows sagittal slices. The signal intensity of the $T_{1}$-weighted MRI was enhanced prominently 1 day after systemic administration of $\mathrm{MnCl}_{2}$ in the rat. There were characteristic signal enhancements that were large in the olfactory bulb (OB), hippocampus, cerebellum, and pituitary. Reprinted from Aoki et al. (44), copyright 2004, with permission from Elsevier. 


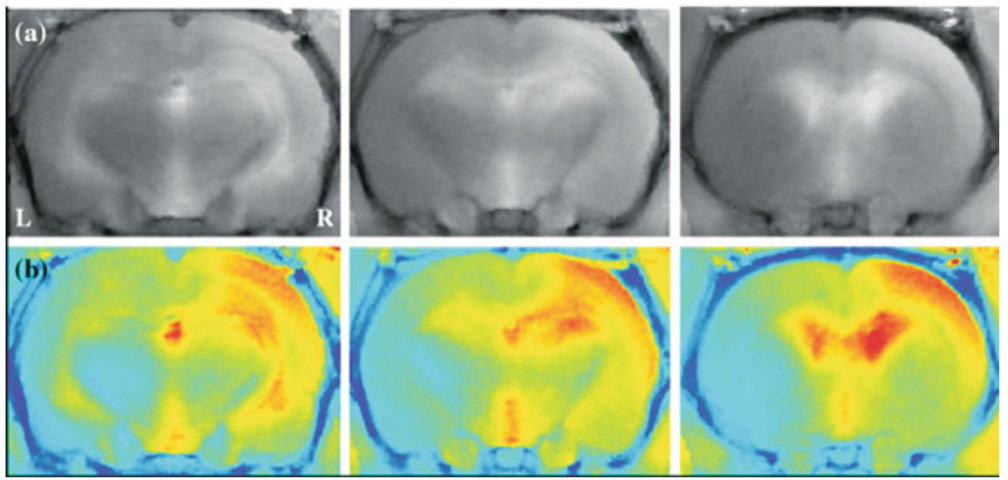

Fig. 7.2.

Three consecutive slices of the averaged $\mathrm{Mn}^{2+}$-enhanced $\mathrm{T}_{1}$ WIs under urethane anesthesia a. $\mathrm{Mn}^{2+}$ enhancement was observed in right cortical barrels. The color maps of the averaged $\mathrm{Mn}^{2+}$-enhanced $\mathrm{T}_{1} \mathrm{WIs}$ b. Reprinted from Weng et al. (50), copyright 2007, with permission from Elsevier. 


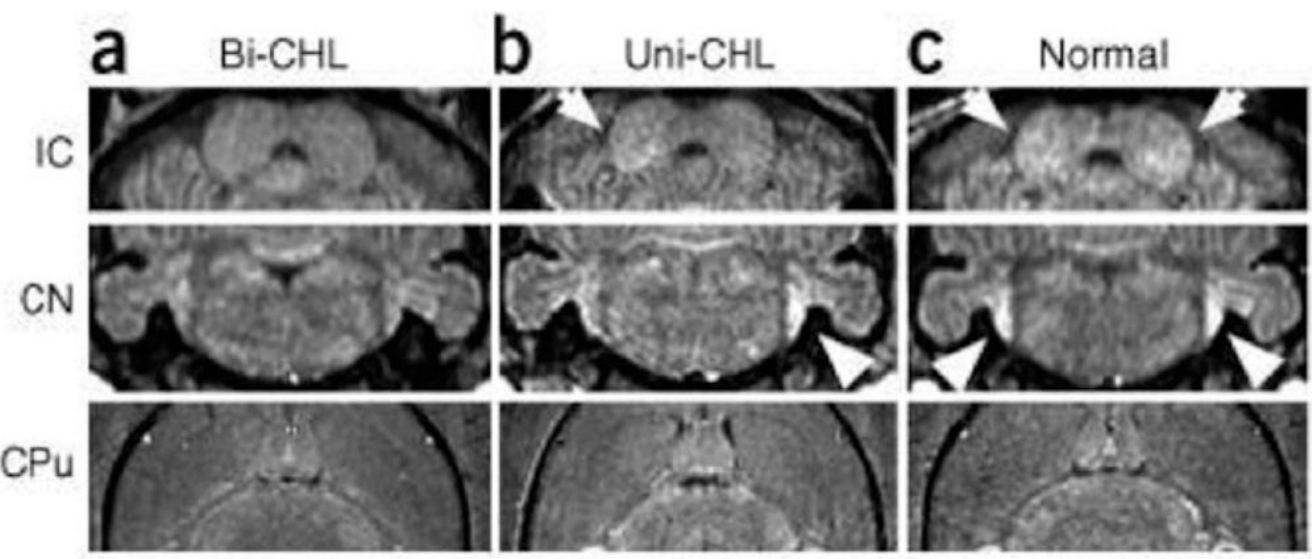

Fig. 7.3.

MEMRI enhancement in brainstem auditory nuclei was altered in mice with conductive hearing loss (CHL). Comparisons of individual mice with bilateral CHL (bi-CHL) (a), mice with unilateral CHL (uni-CHL) (b), and normal mice (c) demonstrated marked differences in MEMRI signals in the cochlear nucleus (CN) (arrow heads) and inferior colliculus (IC) (arrows), but not in non-auditory caudate putamen $(\mathrm{CPu})$. Adapted by permission from (48), copyright 2005. 

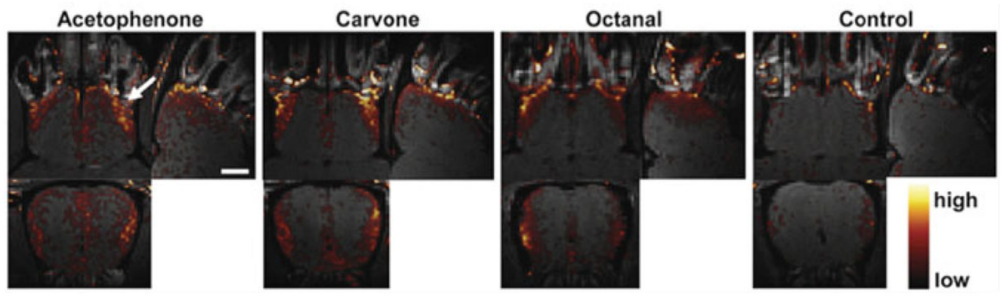

Fig. 7.4.

Detecting odor-dependent $\mathrm{Mn}^{2+}$ enhancement in mouse olfactory bulb by MRI. MEMRI maps after stimulation by acetophenone, carvone, octanal, and control in four mice, respectively, show distributed enhancement in the glomerular layer with each odorant having its own distinct spatial pattern. High signal change at the interface between the olfactory nerve layer and olfactory turbinates (arrow) indicates where $\mathrm{Mn}^{2+}$ flowed in. Scale bars represent $1 \mathrm{~mm}$. Reprinted from Chuang et al. (52), copyright 2009, with permission from Elsevier. 

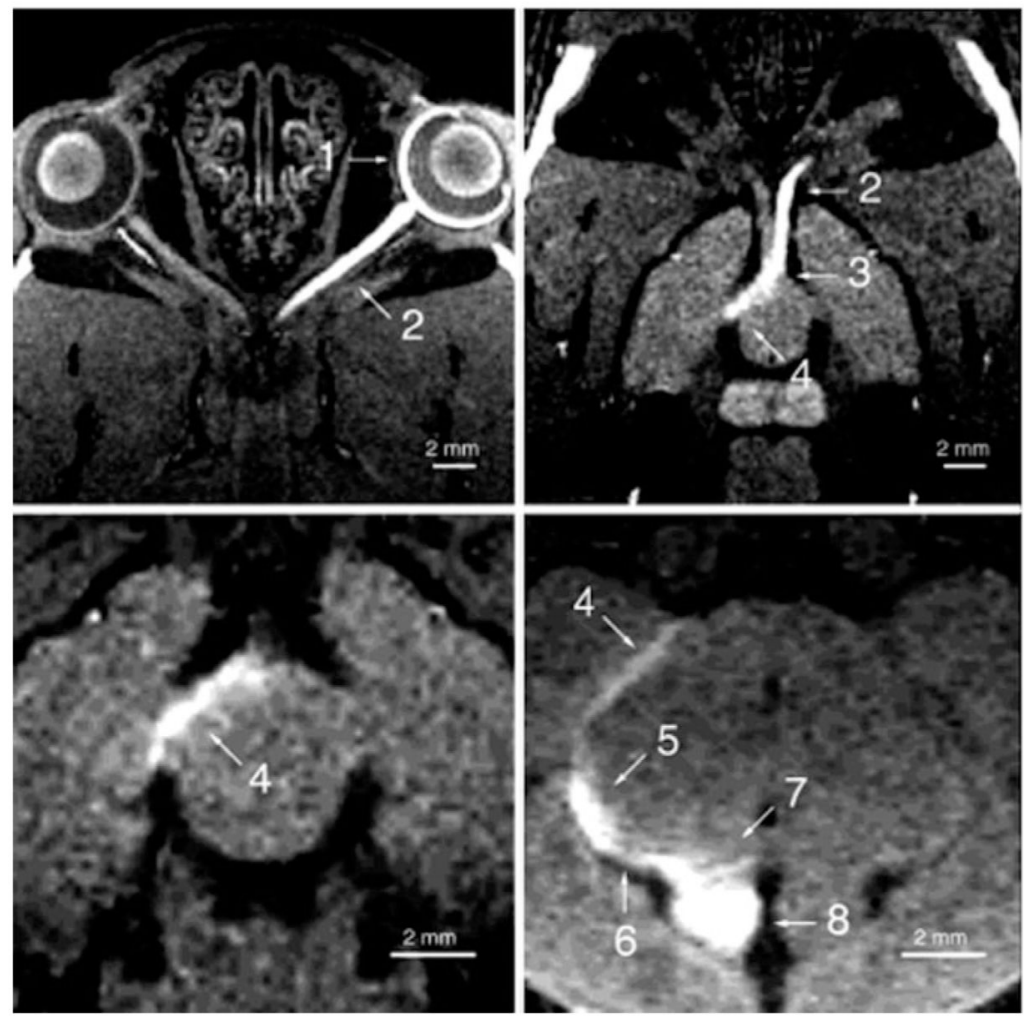

Fig. 7.5.

Signal enhancement of the rat visual pathway ( $24 \mathrm{~h}$ after $\mathrm{Mn}^{2+}$-injection into the left eye) in oblique sections $235^{\circ}$ (top left), $210^{\circ}$ (top right), $15^{\circ}$ (bottom left), and $137.5^{\circ}$ (bottom right) relative to a transverse reference plane. Enhanced structures are (1) left retina, (2) left optic nerve, (3) optic chiasm, (4) right optic tract, (5) right lateral geniculate nucleus, (6) right brachium of the superior colliculus, (7) right pretectal region, and (8) right superior colliculus. Reprinted from (62), copyright 2001, with permission from John Wiley \& Sons, Inc. 


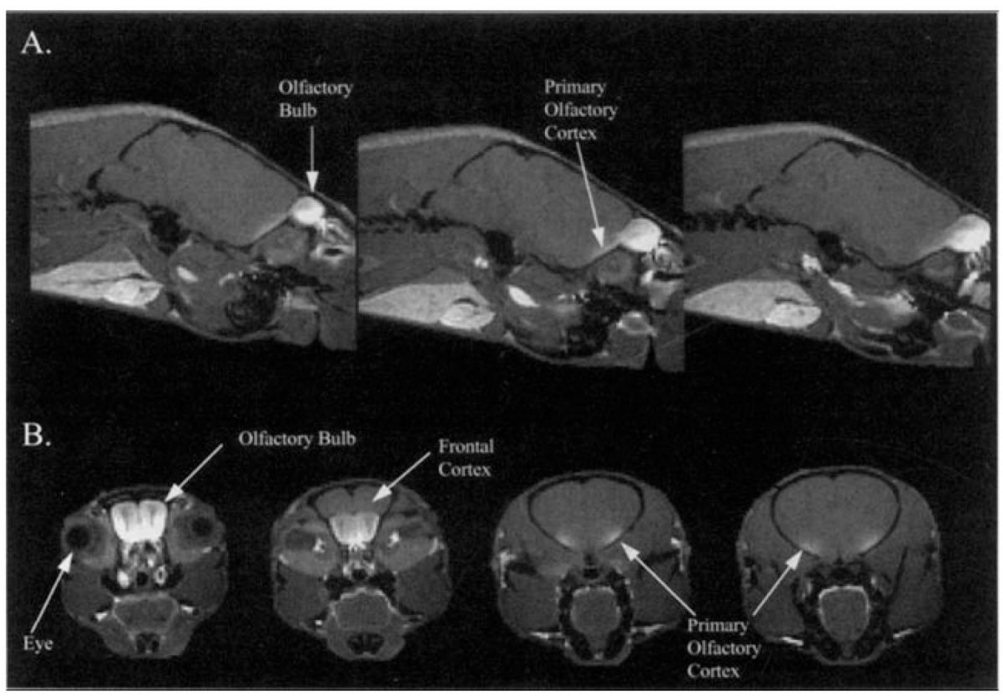

Fig. 7.6.

a Three sagittal slices of a mouse treated with $\mathrm{Mn}^{2+}$ in the naris from a representative 3D $T_{1}$-weighted MRI sequence. Note the highlighting of the olfactory bulb as well as the primary olfactory cortex leading from the bulbs. b Four axial slices from the same mouse treated with $\mathrm{Mn}^{2+}$ in the naris from a 3D $T_{1}$-weighted MRI sequence. Note the highlighting of the outer layers of the olfactory bulbs where the olfactory glomeruli are located. In addition, the enhanced contrast continues caudally into the primary olfactory cortex. Due to the length of the scan, mice were sacrificed before 3D imaging. Reprinted from (3), copyright 1998, with permission from John Wiley \& Sons, Inc. 


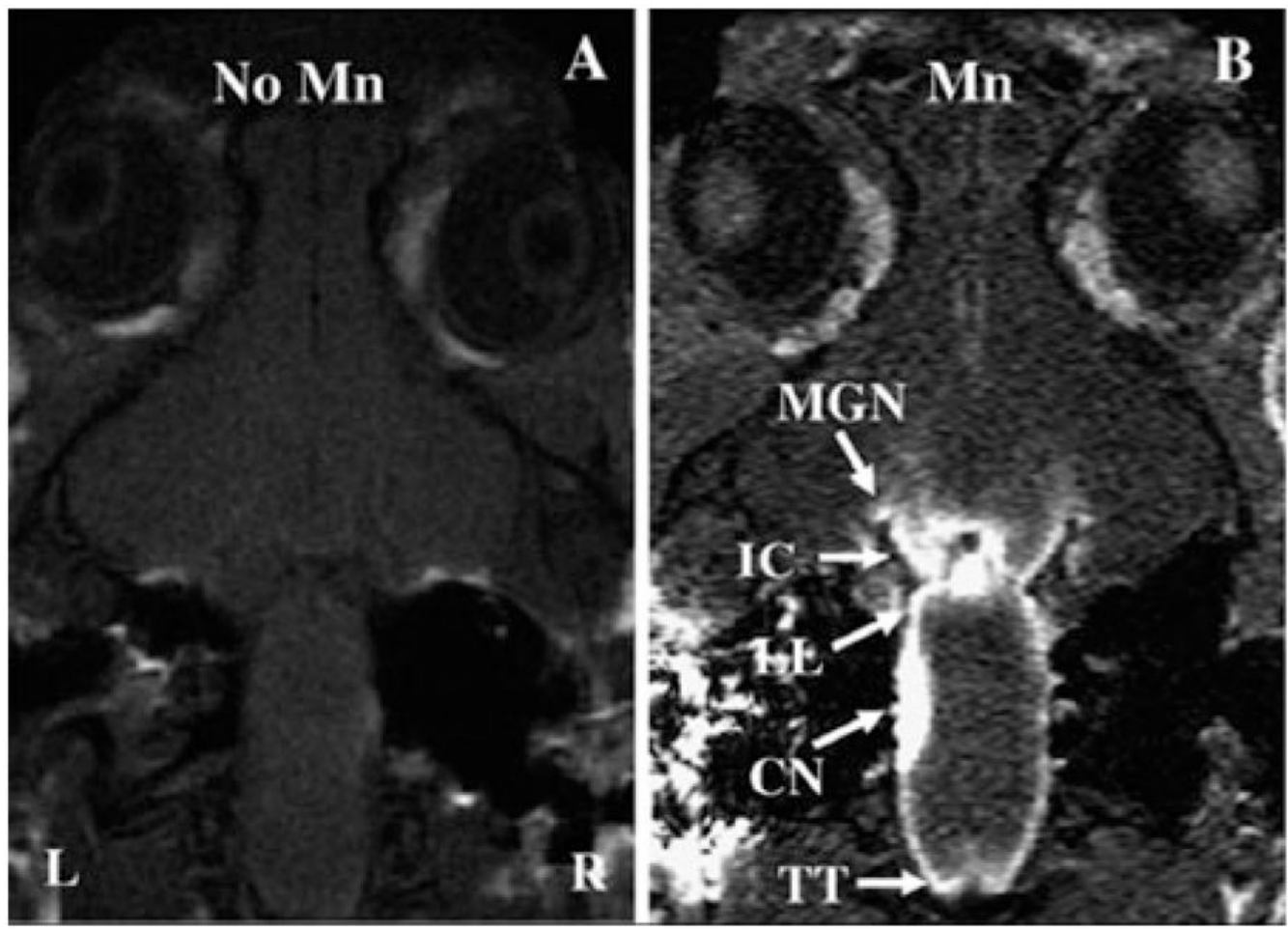

Fig. 7.7.

$T_{1}$-weighted, 2D spin-echo MR image (A) before $\mathrm{MnCl}_{2}$ administration and $T_{1}$-weighted, $3 \mathrm{D}$ gradient-echo image (B) after $12 \mathrm{~h}$ of $\mathrm{MnCl}_{2}$ administration at the left cochlea in the guinea pig. The images' orientation was obtained at the coronal section, and the voxel resolution was $195 \times 195 \times 200 \mu \mathrm{m}(3)$. The post-injection image shows signal enhancement of the auditory pathway. Enhanced structures are as follows: (a) cochlear nucleus $(\mathrm{CN}),(\mathbf{b})$ lateral lemniscus (LL), (c) inferior colliculus (IC), (d) medial geniculate nucleus (MGN), and (e) trigeminal tract (TT). Reprinted from Lee et al. (63), copyright 2007, with permission from Elsevier. 